\title{
IMPROVING THE RELIABILITY OF UPS CENTRAL ASIA IMPLEMENTATION OF FACTS DEVICES
}

\author{
Shukhrat Khamidov ${ }^{1 *}$, Sunnatilla Tillaev ${ }^{1}$, Bahrom Normuratov ${ }^{1 *}$ \\ Tashkent State Technical University named after Islam Karimov, Department of Power Plants, Networks and Systems. \\ 100095, 2 University street, Tashkent, Uzbekistan
}

\begin{abstract}
The article analyzes the issues of increasing the reliability, stability, improving the control of power flows in electrical networks in the Unified Power System of Central Asia on the basis of the introduction of the Flexible AC Transmission Systems (FACTS) technology. The solution of the problems of regulation of operating parameters of electrical sistems is considered. An assessment of the economic effect from the introduction of FACTS technology in the energy system of Uzbekistan has been carried out.
\end{abstract}

\section{Introduction}

The electrical regimes of the Unified Power System of Central Asia (UPS CA) were built on the basis of the need to ensure the interconnection of energy and irrigation in the countries of the region.

Taking into account the pace of economic development, the needs of the countries of the region for electricity by 2035 will increase on average 2 times compared to the current year, which imposes requirements for ensuring the reliability of the functioning of the UPS CA.

To cover the growing needs for electricity, over the past few years, 7 combined-cycle plants with a total installed capacity of more than $3.5 \mathrm{GW}$, a 150 MW power unit for burning high-ash coal have been commissioned in the energy system of Uzbekistan, work is underway to build CCGT with a total capacity of more than $2 \mathrm{GW}$.

The first two generators of the Rogun HPP were commissioned in Tajikistan.

Solar and wind power plants, small and medium hydroelectric power plants with a capacity of more than $100 \mathrm{MW}$ have been built in the energy system of Kazakhstan.

In the power systems of Uzbekistan and Tajikistan, work is underway to create another $500 \mathrm{kV}$ ring, which will significantly increase the reliability of the power system due to the appearance of 1000 MW of additional power reserves required for the peak loads of the UPS CA.

The Turkmen energy system has built a $500 \mathrm{kV}$ line from the Atamurat substation to the Afghan border in the Andkhoy region.

Afghanistan is building a TL $220 \mathrm{kV}$ from Andkhoy to Puli-Khumri.

An option is being considered to improve the reliability of power supply to consumers in Kazakhstan by strengthening the connection between the North and South of the republic by building a direct current line [1-3].

\section{Tasks of Efficient Management of UPS CA}

In recent years, power grids have been significantly strengthened in the UPS CA, and generating capacities have increased. At the same time, the electric regime in the Association is carried out under conditions that do not always allow ensuring the voltage levels at network nodes in accordance with the standards. Problems persist with the throughput of a number of cross-sections between power systems, the delivery of "locked" capacities of individual power plants, and the provision of the required capacity reserve in connection with the expected introduction of solar and wind power plants (more than $2 \mathrm{GW}$ ) with a variable generation pattern. Such "bottlenecks" affect the reliability of the UPS $\mathrm{CA}$, the provision of normal operating parameters both in the seasonal and in the daily period.

\section{Problem solving regulation of operating} parameters

In order to solve the problems arising in the provision of reliable and high-quality power supply to consumers, the UPS CA is carrying out work to improve the methods and means of power flow control in the high-voltage networks based on the technology of FACTS [2-4].

FACTS technology is a family of devices, each of which can be used both individually and in interaction with other devices to control interrelated parameters of the electric power system. The goal of FACTS technology is to improve the control of power flows in both steady state and transient power systems [4-8]. 


\section{Main part}

In general, the FACTS technology allows you to obtain various corrective actions depending on the conditions of a specific control task. It is subdivided into types with different corrective actions depending on the conditions of a specific control task.

To comply with voltage limits, types SVC, STATCOM and TCSC are used, to thermal limits TCSC, SSSC and UPFC, to improve stability of system - TCSC, SSSC. The UPFC type is a highly efficient FACTS device for controlling active and reactive power in transmission lines, changing line capacity, controlling line voltage. The use of additional energy storage, for example, a superconducting inductive energy storage (SPINE), through DC coupling can provide a significant increase in the efficiency of the UPFC. Unique properties of SPINE are the possibility of almost instantaneous transition from the mode of energy storage to the mode of its delivery, high speed of power take-off [2-8].

Modeling the use of the FACTS technology, in particular, of the SVC, STATCOM types, made it possible to ensure effective maintenance of voltage in the control power nodes, to introduce power flows across the sections of the network into the permissible range.

In the power systems of UPS CA, the voltage graphs at the control points are approved quarterly (Table 1, Fig. 1).

Table 1. Approved quarterly voltage schedule at control points of CA UPS

\begin{tabular}{|l|c|c|c|c|}
\hline \multicolumn{1}{|c|}{$\begin{array}{c}\text { Objects (dispatching } \\
\text { names) }\end{array}$} & Equipment & $\begin{array}{c}\text { Approved voltage } \\
\text { fluctuation limits, } \\
\mathrm{kV}\end{array}$ & $\begin{array}{c}\text { Voltages on } \\
\text { demand of } \\
\text { systems, } \mathrm{kV}\end{array}$ & $\begin{array}{c}\text { Emergency } \\
\text { minimum, } \\
\mathrm{kV}\end{array}$ \\
\hline Tashkent TPP (GES - 2) & Busbar 500 & $503 \div 523$ & $503 \div 523$ & 475 \\
& Busbar 220 & $226 \div 236$ & $226 \div 236$ & 205 \\
\hline \multirow{2}{*}{ Syrdarya TPP (GES - 20) } & Busbar 500 & $515 \div 525$ & $515 \div 525$ & 475 \\
& Busbar 220 & $242 \div 252$ & $242 \div 252$ & 215 \\
\hline Navoi TPP (GES - 17) & Busbar 220 & $228 \div 240$ & $228 \div 240$ & 215 \\
\hline Toktogul HPP & Busbar 500 & $503 \div 525$ & $503 \div 525$ & 475 \\
\hline \multirow{2}{*}{ Substation Frunzenskaya } & Busbar 500 & $495 \div 525$ & $495 \div 525$ & 475 \\
\hline Substation Almaty & Busbar 220 & $230 \div 240$ & $230 \div 240$ & 210 \\
\hline Zhambyl TPP & Busbar 500 & $500 \div 525$ & $500 \div 525$ & 475 \\
\hline
\end{tabular}

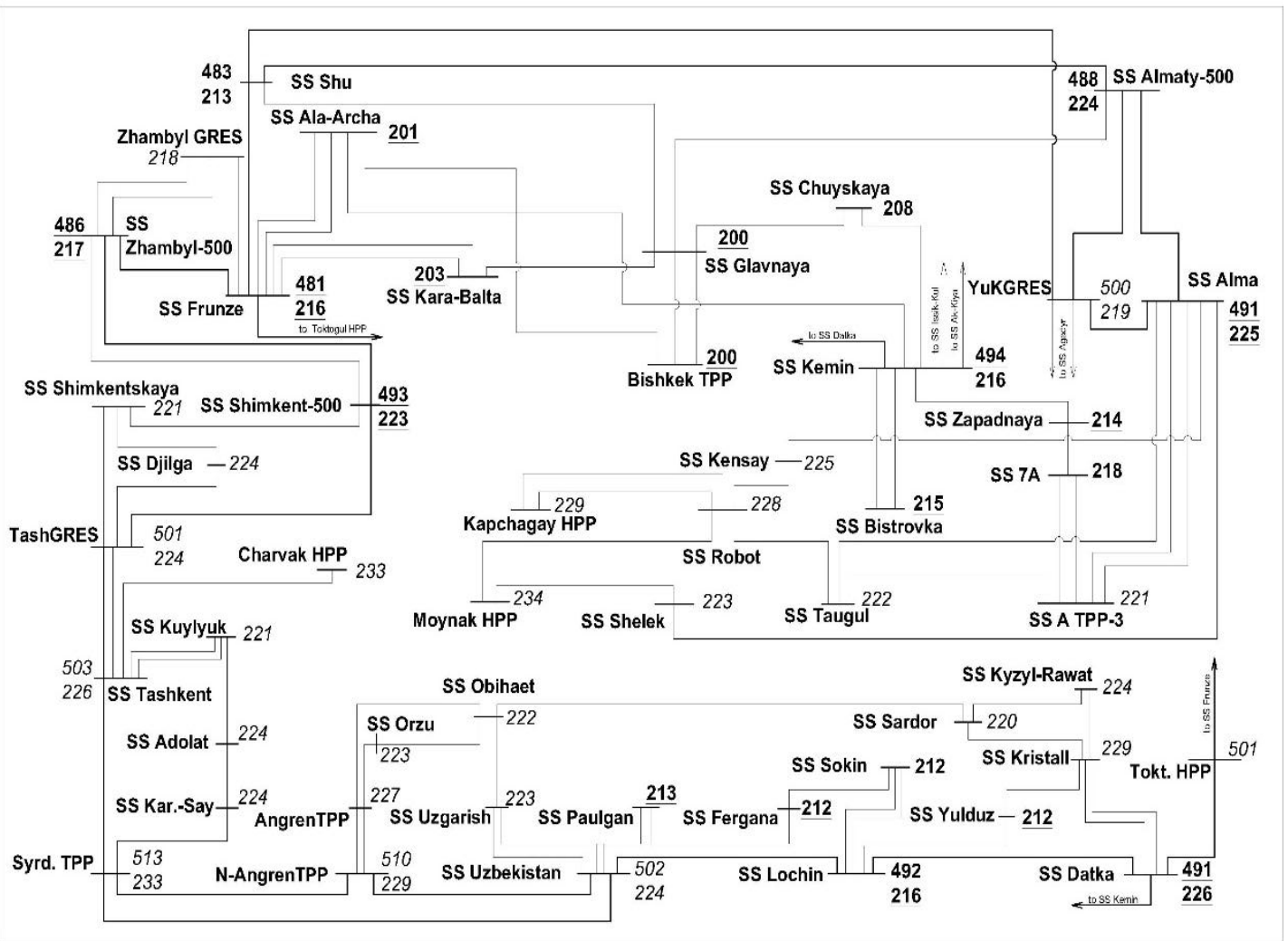

Fig.1. Fragment of the diagram of 220-500 kV networks and voltage in the nodes of UPS CA Voltage levels are given for normal circuit and normal mode. 
Table 2, along with the approved schedules, shows the actual values of voltages in the reference nodes of the UPS CA.

Table 2. Deviations of actual voltages from the approved values at control points of UPS CA

\begin{tabular}{|l|l|c|c|}
\hline \multicolumn{1}{|c|}{$\begin{array}{c}\text { Objects } \\
\text { (dispatching names) }\end{array}$} & Busbars & $\begin{array}{c}\text { Approved } \\
\text { voltage } \\
\text { limits, } \mathrm{kV}\end{array}$ & $\begin{array}{c}\text { Actual } \\
\text { voltage, } \mathrm{kV}\end{array}$ \\
\hline Tashkent TPP (GES-2) & Busbar 500 & $503 \div 523$ & 501,7 \\
& Busbar 220 & $226 \div 236$ & 224,72 \\
\hline Syrdarya TPP (GES-20) & Busbar 500 & $515 \div 525$ & 513,91 \\
& Busbar 220 & $242 \div 252$ & 233,33 \\
\hline Navoi TPP (GES-17) & Busbar 220 & $228 \div 240$ & 235,83 \\
\hline Toktogul HPP & Busbar 500 & $503 \div 525$ & 501,46 \\
\hline Substation Frunzenskaya & Busbar 500 & $495 \div 525$ & 481,07 \\
\hline Substation Almaty & Busbar 220 & $230 \div 240$ & 216,13 \\
\hline Zhambyl GRES & Busbar 500 & $500 \div 525$ & 488,46 \\
\hline
\end{tabular}

As can be seen from Table 2, only at HPP-20 the voltage is within the approved range. The voltage values of other nodes approached the emergency ones, the voltages of other nodes of the UPS CA deviate significantly from normal values. Thus, the voltage at SS Shu was $484 \mathrm{kV}$, SS Zhambyl - 486 $\mathrm{kV}$, at CHP Bishkek - $200 \mathrm{kV}$, which indicates the insufficient efficiency of the existing control systems and in some cases the lack of capabilities and appropriate devices for adjusting the mode parameters. As the operating experience shows, in the UPS CA the mode is carried out under conditions of limited throughput capacity of a number of intersystem transmission lines. Table 3 provides relevant information.

Table 3. Power flows by individual sections of the UPS CA

\begin{tabular}{|l|c|c|c|}
\hline \multicolumn{1}{|c|}{$\begin{array}{c}\text { Dispatcher } \\
\text { section name }\end{array}$} & $\begin{array}{c}\text { Permissible } \\
\text { flow, MW }\end{array}$ & $\begin{array}{c}\text { Actual over- } \\
\text { current, MW }\end{array}$ & Excess, MW \\
\hline $\begin{array}{l}\text { SS Tashkent-Tashkent TPP, } \\
\text { Tashkent TPP-SS Tashkent-220, } \\
\text { SS Yuksak-SS Kuylik }\end{array}$ & 700 & 1015 & 315 \\
\hline $\begin{array}{l}\text { SS Frunze-SS Shu, } \\
\text { SS Almaty-SS Glavnaya, } \\
\text { SS Kemin-SS Zapadnaya, } \\
\text { SS YuKGRES-SS Chiganak }\end{array}$ & 1100 & 1434 & 343 \\
\hline $\begin{array}{l}\text { SS YuKGRES-SS Agadyr, } \\
\text { SS Semey - SS Aktogay }\end{array}$ & 1900 & 2134 & 234 \\
\hline $\begin{array}{l}\text { Syrdarya TPP-SS Uzbekistan, } \\
\text { Novo-Angren TPP-SS Uzbekistan, } \\
\text { Toktogul HPP-SS Datka, }\end{array}$ & & & \\
SS Datka-SS Kemin, & 1500 & 1980 & 480 \\
Angren TPP-SS Orzu, & & & \\
Angren TPP-SS Obihaet & & & \\
\hline
\end{tabular}

It follows from Table 3 that a number of networks of the UPS CA are subject to overloads that affect the stability of the power system. In this situation, control and maintenance of stability standards are functionally ensured by FACTS devices of types TCSC and SSSC by influencing the reactance of power lines. Power flow control and compliance with thermal limits are provided by FACTS technologies of types TCSC, SSSC, UPFC by adjusting line reactance's, phase angle and increasing transmission capacity. To assess the operation of the FACTS technology in relation to the UPS CA, the modes of the Fergana part of the UPS CA were investigated, the power supply of which is carried out through four $500 \mathrm{kV}$ overhead lines and two $220 \mathrm{kV}$ overhead lines (Fig.1).

Allowable power flow along the section L-503 (Syrdarya TPP - SS Uzbekistan), L-524 (NovoAngren TPP - SS Uzbekistan), L-554, L-555, L-25 Obihaet (Angren TPP - SS Orzu), L - Orzu (Angren TPP - SS Orzu) - is $1500 \mathrm{MW}$. regime for:

In particular, the calculations of the electrical

a) repair of L-503, emergency shutdown of L524 and installation of SVC and STATCOM at 220 $\mathrm{kV}$ substations "Sardor", "Obikhayot", "Kyzyl Rawat" and "Uzbekistan-220";

b) repair of L-503, emergency shutdown of L524 and in the presence of SVC and STATCOM at substations "Uzbekistan-500" and "Lochin" showed 
that as a result of the voltage at the network nodes were established within acceptable limits (Table 4).

Table 4. Voltage regulation. Effect of FACTS installation in UPS CA

\begin{tabular}{|l|c|c|}
\hline \multirow{2}{*}{$\begin{array}{c}\text { Installation location } \\
\text { FACTS }\end{array}$} & $\begin{array}{c}\text { Vefore installing } \\
\text { FACTS }\end{array}$ & $\begin{array}{c}\text { After installing } \\
\text { FACTS }\end{array}$ \\
\cline { 2 - 3 } & 191 & 219 \\
\hline SS-220 Obihayot & 190 & 222 \\
\hline SS-220 Sardor & 187 & 220 \\
\hline SS Uzbekiston-220 & 199 & 227 \\
\hline
\end{tabular}

In the event of an emergency shutdown of L-524 (Novo-Angren TPP - SS Uzbekistan) during the repair of L-503, the capacity of the L-25- Obihayot and L-Orzu lines included in the L-503, L-524, L-555, L-554, LOrzu and L-25- Obihayot, is insufficient, which leads to low voltages in the network nodes. Installation of FACTS devices of SVC and STATCOM types at Substation-220 "Obihayot" and Substation-220 "Sardor" unloads the named lines of $220 \mathrm{kV}$ to permissible limits (Table 5).

Table 5. Regulation of flows. Effect of FACTS installation in UPS CA

\begin{tabular}{|c|c|c|c|}
\hline \multirow{2}{*}{$\begin{array}{c}\text { Repair mode L-503 } \\
\text { (Syrdarya TPP-Substation } \\
\text { Uzbekiston) }\end{array}$} & \multirow{2}{*}{$\begin{array}{l}\text { Permissible } \\
\text { flow, MW }\end{array}$} & \multicolumn{2}{|c|}{ Active power flow } \\
\hline & & $\begin{array}{c}\text { Before off } \\
\text { L-524 }\end{array}$ & $\begin{array}{c}\text { After off } \\
\text { L-524 }\end{array}$ \\
\hline L-Orzu & 350 & 109 & 220 \\
\hline $\mathrm{L}-25-\mathrm{O}$ & 350 & 114 & 230 \\
\hline
\end{tabular}

Based on the functional purpose, the reverse flow of reactive power when the line "Syrdarya TPP SS Uzbekistan-500" is taken out for repair, is effectively regulated by FACTS devices such as UPFC, SSSC, TCPAR installed on the $220 \mathrm{kV}$ overhead lines "L-Orzu" and "L-25-Obihayot" (Table 6).

Table 6. Reactive power mode in the Fergana part of the UPS CA.

\begin{tabular}{|c|c|c|}
\hline \multicolumn{3}{|c|}{ Reactive power flow values, MVAr } \\
\hline $\begin{array}{c}\text { Repair mode L-503 } \\
\text { (Syrdarya TPP- } \\
\text { Substation Uzbekiston) }\end{array}$ & $\begin{array}{c}\text { Before off } \\
\text { L-524 }\end{array}$ & $\begin{array}{c}\text { After off } \\
\text { L-524 }\end{array}$ \\
\hline L-Orzu & -4 & 66 \\
\hline L-25-O & -5 & 71 \\
\hline
\end{tabular}

As a result of the installation of STATCOMtype FACTS devices at the $220 \mathrm{kV}$ substations "Sardor", "Obihayot", "Kyzyl Rawat" and "Uzbekistan-220", an increase of up to $30 \%$ of the limits of the transmitted power along the remaining lines L-25-O, L-Orzu, and a decrease in the required volume of load limitation by $240 \mathrm{MW}$, which made it possible to halve the possible shortage of electricity to consumers.

The obtained results were accepted for use in JSC National Electric Networks of the Ministry of Energy of the Republic of Uzbekistan. The estimated economic effect when installing FACTS devices is assessed as a result of maintaining voltages, regulating flows and preventing emergency mode in the networks of UPS CA.

\section{Conclusion}

The high technical capabilities of the FACTS technology stimulate the development of mechanisms for innovative activity in the field of intellectualization of the electric power industry in Uzbekistan and the introduction of this technology.
Research and analysis of the effectiveness of modern types of FACTS technology in the tasks of managing the unified power system of Central Asia, allow you to obtain the effects of increasing stability and regime controllability, depending on the specific task. In UPS CA low voltage problems in power systems under heavy load; high voltage at low load; high voltage after automatic reclosure; low voltage after a failure are effectively solved by using FACTS technology types SVC, STATCOM, TCSC.

The presence of problems associated with restrictions on power flows in Fergana, Tashkent, North, and South-Western power centers are solved by installing FACTS devices such as TCSC, SSSC, UPFC in them.

Taking into account the above operating problems in the nodes and sections of the UPS CA, it is advisable to introduce the FACTS technology, which opens up new opportunities for maintaining the nodal voltages within the standard limits, controlling the power flows in the power transmission lines while ensuring the transmission capacity of the lines up to the limit of the thermal resistance of wires, and increasing the stability of the electrical system. The choice of a specific type of 
FACTS that has the required corrective actions (reactive power supply, power transmission line reactive resistance reduction, reactive power withdrawal) is carried out depending on typical operating problems of UPS CA.

\section{References}

1. Shamsiev B.Kh. Current status, challenges and outlook of energy connectivity development in North and East Asia. //Energy connectivity in North and Central Asia: EPC-CIS, SCO. Second Meeting of Experts Working Group on Energy Connectivity. ESCAP. - Beijing, Desember, 2018.

2. Misrikhanov M. Sh., Khamidov Sh. V. perspective development of the electric power industry of the Central Asian ECO with the introduction of FACTS devices and renewable energy sources. // Methodological issues of reliability research of large power systems: Issue 70 . Methodological and practical problems of reliability of power systems. / Book 1 / ed. by N. I. Voropay. Irkutsk: ISEM SB RAS, 2019, 371 p. -P. 37-45.

3. Khamidov Shukhrat. To modeling of FACTS devices and their application on the Intersystem Relations of Integrated Power System of Central Asia. // International Journal of Advanced Research in Science, Engineering and Technology. India, Vol. 6, Iss. 10, October 2019. -P. 11239-11246.

4. Misrikhanov M. Sh., Ryabchenko V. N., Khamidov Sh. V. Calculation of power flows in electric networks with FACTS devices/ Ivanovo state power Engineering University. - Ivanovo, 2018. $208 \mathrm{c}$.

5. Song, Y. H. Flexible AC Transmission Systems (FACTS)/ Y. H. Song, A. T. Johns. London: IEEE Press, 1999.

6. Acha, E. A. FACTS: Modeling and Simulation in Power Networks/ Acha, E.A. [and ethers] - John Wiley \& Sons, 2004.

7. Hingorani, N. G. Understanding FACTS: Concepts and Technology of Flexible AC Transmission Systems. IEEE Press, 2000.

8. Sitnikov V. F. Improvement of methods and tools for managing modes of electric power systems based on flexible power transmission elements (FACTS). JSC "Institute "Energosetproekt" and the Department "Automatic control of electrical power systems" of the Ivanovo State Power Engineering University, Ivanovo, 2009. - P. 2-7. 